Aim of the study: To identify predictors of quality of life (QOL) in head and neck cancer patients prior to cisplatin chemotherapy and radiotherapy treatment.

Material and methods: A cross-sectional study at a Clinical Oncology department of a teaching hospital in the state of São Paulo, Brazil, from September 2011 to October 2012 was performed. QOL was assessed using the University of Washington OOL Questionnaire. Demographic and clinical characteristics were obtained through interviews with patients and collected from medical records. Multivariate linear regression was used to determine the association between $\mathrm{QOL}$ scores and patient-related factors.

Results: We studied 48 head and neck cancer patients, who were mostly white $(77.1 \%)$, males $(83.3 \%)$, with pharyngeal cancers $(66.7 \%)$, cancers with stage T4 (45.8\%) and N1 (31.2\%) tumours, and classified with a Karnofsky Performance Status (KPS) of $90 \%$ (37.5\%). Patients had excellent scores for saliva $(96.2 \pm 13.5)$ and shoulder (93.6 \pm 17.9$)$, with pain and anxiety being the most affected domains $(59.6 \pm 32.4$ and $57.5 \pm 39.2$, respectively). A significant relationship of KPS and Tstage with overall QOL score was noted. The population with lowest overall QOL score was those who had low KPS scores and T4 tumours.

Conclusions: Head and neck cancer patients prior to cisplatin chemotherapy and radiotherapy treatment, with a low KPS and staged as T4 tumours, have worse overall QOL, and special attention should be given to these patients.

Key words: quality of life, head and neck neoplasms, Karnofsky performance status.

Contemp Oncol (Pozn) 2015; 19 (2): 148-153 DOI: $10.5114 /$ wo.2015.51420

\section{Evaluation of the quality of life of patients before treatment of squamous cell carcinoma of the head and neck by means of chemoradiotherapy}

\author{
Marília Berlofa Visacri ${ }^{1}$, Graziele Baldan Ferrari², Rafaela Pimentel ${ }^{3}$ \\ Rosiane D. Fátima Lopes Ambrósio4, Carmen Silvia Passos Lima ${ }^{5}$, \\ Priscila Gava Mazzola², Patricia Moriel ${ }^{2}$
}

${ }^{1}$ School of Medical Sciences (FCM), University of Campinas (UNICAMP), Brazil ${ }^{2} S$ chool of Pharmaceutical Sciences (FCF), University of Campinas (UNICAMP), Brazil ${ }^{3}$ Institute of Biology, University of Campinas (UNICAMP), Brazil

Department of Pharmacology, School of Medical Sciences (FCM), University of Campinas (UNICAMP), Brazil

Department of Clinical Medicine, School of Medical Sciences (FCM), University of Campinas (UNICAMP), Brazil

\section{Introduction}

Head and neck cancer, which is the fifth most common cancer worldwide, refers to primary tumours arising out of the lip, oral cavity and pharynx, nasal cavity and paranasal sinuses, inner ear, and larynx.

It is known that head and neck cancer patients are prone to have a poor health-related quality of life (QOL) due to significant changes in vital functions related to food, communication, and social interaction, as well as aesthetic effects [1]. The function and appearance of the head and neck region are crucial to self-image and QOL, as the patient's physical, psychological, and social wellbeing are heavily influenced by deformity and dysfunction resulting from these tumours [2].

The Karnofsky performance status (KPS) is a standard manner of measuring the ability of cancer patients to perform ordinary tasks [3]. In several studies this functional status has shown a valid correlation with QOL $[4,5]$. Moreover, some disease-related variables are already known to have an impact on QOL, such as site, stage, and treatment of the disease $[6,7]$.

Based on this finding, we decided to study the relationship between patient-related factors and QOL (and its domains) using the University of Washington QOL Questionnaire (UWQOL).

\section{Material and methods}

This is a cross-sectional study conducted at the Clinical Oncology department (where patients were referred for chemotherapy treatment) of a teaching hospital in the state of São Paulo, Brazil. The inclusion period was from September 2011 to October 2012. The Research Ethics Committee of our institution approved this study.

\section{Eligibility criteria}

We used non-probabilistic consecutive sampling. Patients were eligible for the study if they had squamous cell carcinoma of the head and neck (primary tumour), and if they received high-dose cisplatin chemotherapy (80 or $100 \mathrm{mg} / \mathrm{m}^{2}$ ) and concurrent radiotherapy as therapeutic conduct. 
Patients who had undergone previous treatment of the tumour (surgery, chemotherapy, and radiotherapy), with severe psychiatric problems, or who refused to participate were excluded.

\section{Patient-related factors}

The following demographic and clinical characteristics were obtained through interviews with 48 patients (mean age 55.7 years; $83.3 \%$ men) and collected from medical records: age, gender, race, body mass index (BMI), education level, marital status, work situation, drinking category [8], smoking category [9], feeding tubes and tracheostomy, primary tumour site, and tumour stage [T stage indicates tumour extension, rating from 1 (the best condition) to 4 (the worst condition) and $\mathrm{N}$ stage indicates metastasis in the lymph nodes, rating from 0 (the best condition) to 3 (the worst condition)].

For the measurement of functional status, the KPS was used, which is a standard manner of measuring the ability of cancer patients to perform ordinary tasks [3]. Its scores range from 0 to 100 (\%); a high score indicates that the patient is better able to perform daily activities.

\section{Quality-of-Life Questionnaire}

Quality-of-Life Questionnaire was assessed using the University of Washington QOL Questionnaire (UWQOL) (version 4.0) [1, 10], a disease-specific instrument for head and neck cancer patients; it was previously adapted into Portuguese and validated for the Brazilian population [11]. The UWQOL is composed of 12 multiple-choice questions related to specific domains of quality of life as follows: pain, appearance, activity, recreation, swallowing, chewing, speech, shoulder, taste, saliva, mood, and anxiety. Each question has three to five response categories, with scores ranging from 0 (worst condition) to 100 (best condition). The scale thus obtained enabled us to assess each quality of life domain and also in an integrated manner, from the average of 12 domains, by bringing all measures into a global value for each patient (overall QOL).

This instrument was applied on the patient's first day at the Clinical Oncology department when they received a treatment proposal for cancer, as mentioned above. Each patient was administered the questionnaire by the same interviewer, who was previously trained in reading the questions and response options in the questionnaire. All patients were instructed to answer the questions according to the events of the past seven days. The interviewer did not at any time interfere in any manner that could influence the interviewee's answers.

\section{Statistical analysis}

To study the influence of patient-related factors on the values of the overall QOL score and domain scores, we used the Multiple Linear Regression (SAS, 9.2 version, 2002-2008, Cary, NC, USA) model, with stepwise criteria of variable selection. The variables were transformed into ranks due to the lack of normal distribution. $P<0.05$ was considered significant.

\section{Results}

We included consecutively all 48 patients who were referred for high-dose cisplatin and radiotherapy treatment. They were predominantly white males, with a mean age of 55.7 years, a mean BMI within normal limits, with a KPS between $100 \%$ and $70 \%$, heavy smokers and drinkers, had a partner, had advanced pharyngeal tumours, and low socioeconomic status/education level. No patient had distant metastases (Tables 1 and 2).

The scores obtained in the assessment of QOL for the patients studied are shown in Table 3. Before initiating treatment, the studied population had excellent scores for saliva and shoulder; however, pain and anxiety were the most affected domains.

The studied patients' individual characteristics prior to treatment and their relation to overall QOL and their specific domains are shown in Table 4. Significant relationships were noted between: 1) N stage and KPS with pain score - the patients with low pain score were those who had N3 tumours and a low KPS; 2) KPS and T stage with appearance score - patients with low appearance score were those who had T4 tumours and a low KPS; 3) KPS with activity and recreation score - the patients with low activity and recreation scores were those who had a low

Table 1. Patient demographic characteristics $(n=48)$

\begin{tabular}{|c|c|}
\hline Mean age (range), years & $55.7(27-76)$ \\
\hline Mean BMI (range), kg/m² & $21.6(13.7-42.8)$ \\
\hline $\begin{array}{l}\text { Gender } \\
\text { men } \\
\text { women }\end{array}$ & $\begin{array}{c}40(83.3 \%) \\
8(16.7 \%)\end{array}$ \\
\hline $\begin{array}{l}\text { Race } \\
\text { white } \\
\text { non-white }\end{array}$ & $\begin{array}{l}37(77.1 \%) \\
11(22.9 \%)\end{array}$ \\
\hline $\begin{array}{l}\text { Education level } \\
\text { < } 4 \text { years } \\
\text { 4-10 years } \\
\text { secondary }\end{array}$ & $\begin{array}{c}29(60.4 \%) \\
11(22.9 \%) \\
8(16.7 \%)\end{array}$ \\
\hline $\begin{array}{l}\text { Work situation } \\
\text { work } \\
\text { not working due to tumour } \\
\text { not working for other reasons } \\
\text { not evaluated }\end{array}$ & $\begin{array}{c}7(14.6 \%) \\
23(47.9 \%) \\
17(35.4 \%) \\
1(2.1 \%)\end{array}$ \\
\hline $\begin{array}{l}\text { Marital status } \\
\text { with partner } \\
\text { without partner }\end{array}$ & $\begin{array}{l}30(62.5 \%) \\
18(37.5 \%)\end{array}$ \\
\hline $\begin{array}{l}\text { Smoking category } \\
\text { never-smokers } \\
\text { light smokers } \\
\text { moderate smokers } \\
\text { heavy smokers } \\
\text { not evaluated }\end{array}$ & $\begin{array}{c}3(6.3 \%) \\
0(0.0 \%) \\
5(10.4 \%) \\
38(79.1 \%) \\
2(4.2 \%)\end{array}$ \\
\hline $\begin{array}{l}\text { Drinking category } \\
\text { abstainer } \\
\text { light drinkers } \\
\text { moderate drinkers } \\
\text { heavy drinkers } \\
\text { very heavy drinkers } \\
\text { not evaluated }\end{array}$ & $\begin{array}{c}7(14.6 \%) \\
3(6.3 \%) \\
6(12.5 \%) \\
16(33.3 \%) \\
13(27.0 \%) \\
3(6.3 \%)\end{array}$ \\
\hline
\end{tabular}

$B M I$ - body mass index 
KPS; 4) KPS, BMI, and feeding tube with swallowing score - patients with low swallowing scores were those who had a low KPS, low BMI, and feeding tubes; 5) T stage, cancer site, and feeding tube with chewing score - patients with low chewing scores were those who had oral cavity cancers, following pharyngeal cancer, T4 tumours, and feeding tubes; 6) T stage with speech score - patients with low speech scores were those who had T3 and T4 tumours; 7) N stage with shoulder score - patients with low shoulder score were those who had N3 tumours; 8) BMI with taste score - patients with low taste scores were those who had a low BMI; 9) Race with mood score - patients with low mood scores were white people; 10) KPS and gender with anxiety score - patients with low anxiety scores were female and they also had a high KPS; and 11) KPS and T stage with overall QOL score - patients with a low overall QOL score were those who had a low KPS (mean \pm SD of overall QOL scores: $K P S 100 \%=85.6 \pm 16.9, K P S 90 \%=79.1$ $\pm 16.6, \mathrm{KPS} 80 \%=61.7 \pm 16.6, \mathrm{KPS} 70 \%=61.5 \pm 16.3)$ and $\mathrm{T} 4$ tumours (mean \pm SD of overall QOL scores: $T 1=89.3 \pm 18.7$, $T 2=82.7 \pm 16.7, T 3=75.3 \pm 16.3, T 4=66.5 \pm 16.4 ; T 1+T 2+$ $T 3=79.7 \pm 16.3$ vS. $T 4=66.5 \pm 16.4$ ).

\section{Discussion}

Patient-related factors that may influence QOL include gender, age, functional status, and psychological status

Table 2. Patient clinical characteristics $(n=48)$

\begin{tabular}{|c|c|}
\hline \multicolumn{2}{|l|}{ KPS } \\
\hline 100 & 11 (22.9\%) \\
\hline 90 & $18(37.5 \%)$ \\
\hline 80 & 9 (18.8\%) \\
\hline 70 & $10(20.8 \%)$ \\
\hline \multicolumn{2}{|l|}{ Tumour site } \\
\hline pharynx & $32(66.7 \%)$ \\
\hline larynx & $12(25.0 \%)$ \\
\hline oral cavity & $4(8.3 \%)$ \\
\hline \multicolumn{2}{|l|}{ T Stage } \\
\hline $\mathrm{T} 1$ & $4(8.3 \%)$ \\
\hline $\mathrm{T} 2$ & 8 (16.7\%) \\
\hline T3 & $14(29.2 \%)$ \\
\hline $\mathrm{T} 4$ & $22(45.8 \%)$ \\
\hline \multicolumn{2}{|l|}{ N Stage } \\
\hline NO & 11 (22.9\%) \\
\hline N1 & 15 (31.2\%) \\
\hline N2 & $14(29.2 \%)$ \\
\hline N3 & 8 (16.7\%) \\
\hline \multicolumn{2}{|l|}{ Feeding tube } \\
\hline yes & $6(12.5 \%)$ \\
\hline no & $42(87.5 \%)$ \\
\hline \multicolumn{2}{|l|}{ Tracheostomy } \\
\hline yes & $6(12.5 \%)$ \\
\hline no & 42 (87.5\%) \\
\hline
\end{tabular}

[4]. Many studies have been designed to study factors that may predict QOL in head and neck cancer patients during or after several treatments [4, 6, 12-15]. In our study, we attempted to evaluate pretreatment patient-related factors that determined QOL. We found that KPS and tumour extension are the major factors predicting QOL. Gender, race, $\mathrm{BMI}$, feeding tube, $\mathrm{N}$ stage, and tumour site had less influence, and age, tracheostomy, educational level, marital status, work situation, and smoking and drinking category did not influence any QOL domain. It should be emphasised that we used only one instrument to assess QOL and one statistical model; however, because of the scarcity of previous literature studying predictors of QOL using the UWQOL, this study stands out.

Functional status, as measured with the KPS [3], a reliable and valid instrument to assess the functional status of cancer patients [16], has been shown to be positively correlated with QOL $[4,5]$. In studies with lung, colon, and prostate cancer patients, the KPS was also found to be a predictor of QOL [17]. We demonstrated that the KPS was the major and the strongest predictor of QOL prior to treatment, and this was indicated primarily using the UWQOL. KPS was also associated with pain, appearance, activity, recreation, swallowing, and anxiety domains.

Disease-related variables that are considered to influence QOL are site, stage, and treatment of the disease [6, 7]. Site and stage to a large extent determine treatment and hence its impact on QOL $[4,18]$. In our study, another predictor of overall QOL by the UWQOL was the T stage because T4 patients have a lower QOL. The numbers after $T$ describe the tumour size and/or amount of spread into nearby structures. The higher the $T$ number, the larger the tumour and/or the more it has spread into nearby tissues. The $T$ stage contributed to lower scores for appearance, chewing, and speech. However, Terrel et al. [14] and Hammerlid and Taft [18] found that cancer stage was not associated with any of the QOL scales (SF-36, HNQoL, and EORTC QLQ-H\&N35 instruments). It is important to note

Table 3. Specific domains and overall QOL (score: 0 - worst/100 best)

\begin{tabular}{|lccc|}
\hline Domains & Mean \pm SD & Median & Range \\
\hline Pain & $59.6 \pm 32.4$ & 50 & $0-100$ \\
\hline Appearance & $80.7 \pm 22.6$ & 75 & $25-100$ \\
Activity & $72.9 \pm 28.6$ & 75 & $0-100$ \\
\hline Recreation & $73.4 \pm 31.1$ & 100 & $0-100$ \\
\hline Swallowing & $69.4 \pm 35.0$ & 83.5 & $0-100$ \\
Chewing & $64.6 \pm 42.5$ & 100 & $0-100$ \\
Speech & $69.0 \pm 29.6$ & 67 & $0-100$ \\
Shoulder & $93.6 \pm 17.9$ & 100 & $33-100$ \\
\hline Taste & $84.0 \pm 31.6$ & 100 & $0-100$ \\
Saliva & $96.2 \pm 13.5$ & 100 & $33-100$ \\
Mood & $70.8 \pm 30.7$ & 75 & $0-100$ \\
Anxiety & $57.5 \pm 39.2$ & 67 & $0-100$ \\
Overall QOL & $73.7 \pm 16.3$ & 75.5 & $36.8-98.0$ \\
\hline QOL - quality of life; SD - standard deviation & & \\
& & &
\end{tabular}


Table 4. Multiple linear regression for specific domains scores and overall quality of life (only characteristics that were related to quality of life)

\begin{tabular}{|c|c|c|c|c|c|}
\hline Domains & Predictor & Categories & Beta (SE) & $P$ value & $\mathrm{R}^{2}$ \\
\hline \multirow[t]{2}{*}{ Pain } & KPS & - & $0.29(0.12)$ & 0.022 & 0.1084 \\
\hline & N stage & N3 & $-5.32(1.98)$ & 0.011 & 0.1898 \\
\hline \multirow[t]{2}{*}{ Appearance } & KPS & - & $0.30(0.10)$ & 0.007 & 0.2627 \\
\hline & T stage & T4 & $-10.05(4.22)$ & 0.023 & 0.1435 \\
\hline Activity & KPS & - & $0.55(0.09)$ & $<0.001$ & 0.4801 \\
\hline Recreation & KPS & - & $0.56(0.09)$ & $<0.001$ & 0.4838 \\
\hline \multirow[t]{3}{*}{ Swallowing } & KPS & - & $0.24(0.10)$ & 0.023 & 0.0890 \\
\hline & BMI & - & $0.26(0.09)$ & 0.007 & 0.4313 \\
\hline & feeding tube & yes & $-10.44(4.70)$ & 0.032 & 0.0538 \\
\hline \multirow[t]{3}{*}{ Chewing } & feeding tube & yes & $-14.13(4.50)$ & 0.003 & 0.2743 \\
\hline & tumour site & larynx & $16.97(6.01)$ & 0.008 & 0.1655 \\
\hline & T stage & T4 & $-11.65(3.57)$ & 0.002 & 0.1335 \\
\hline \multirow[t]{2}{*}{ Speech } & T stage & $\mathrm{T} 3$ & $-15.28(4.91)$ & 0.003 & 0.2238 \\
\hline & T stage & T4 & $-13.27(4.54)$ & 0.006 & 0.2238 \\
\hline Shoulder & $\mathrm{N}$ stage & N3 & $-3.41(1.23)$ & 0.009 & 0.2899 \\
\hline Taste & BMI & - & $0.24(0.08)$ & 0.005 & 0.1768 \\
\hline Saliva & - & - & - & - & - \\
\hline Mood & race & no white & $9.83(4.52)$ & 0.035 & 0.1037 \\
\hline \multirow[t]{2}{*}{ Anxiety } & KPS & - & $-0.25(0.11)$ & 0.030 & 0.1123 \\
\hline & gender & women & $-10.37(4.87)$ & 0.040 & 0.0923 \\
\hline \multirow[t]{2}{*}{ Overall QOL } & KPS & - & $0.46(0.11)$ & $<0.001$ & 0.4101 \\
\hline & T Stage & T4 & $-11.59(4.37)$ & 0.012 & 0.1077 \\
\hline
\end{tabular}

$B M I$ - body mass index; KPS - Karnofsky performance status; $Q O L$ - quality of life; Beta-estimated value or slope in the regression line; $R^{2}$ - coefficient of determination; SE - standard error of beta

Continuous variables do not have categories (-).

that our sample had a prevalence of advanced tumours (T3 and T4) due to the characteristic of the clinical department in question (in general, patients referred to this antineoplastic treatment are those who are in the major stages of the disease; early stages of disease are referred for surgical resection or radiotherapy alone). Although there were a small number of patients with $\mathrm{T} 1$ and $\mathrm{T} 2$ tumours, the multiple linear regression statistical model was able to demonstrate an influence of tumour size on quality of life.

The N stage describes whether the cancer has spread into nearby lymph nodes. In our study, this category was a predictor of pain and shoulder problems because patients with stage N3 tumours had low pain and shoulder scores. In relation to tumour site, this was a predictor of chewing because patients with larynx cancer had better chewing scores than patients with oral cavity and pharyngeal cancers. We also expected to observe that the cancer site would be related to speech (larynx cancer patients would have worse speech score, as demonstrated by Hammerlid et al. [19]); however, we did not observe this association.

Depression and other psychosocial morbidities such as anxiety occurred frequently in head and neck cancer patients before and after treatment $[20,21]$. These reactions are common because cancer and its treatment have always been associated with the idea of death and suffering. Graeff et al. [4] demonstrated that head and neck cancer patients who exhibit depressive symptoms prior to treatment are at risk for physical/psychological morbidity and poor quality of life after treatment. We demonstrated that gender and race are predictors of anxiety and mood before treatment; women are more prone to anxiety, and white people have an increased risk of depression. We also expected to find gender to be related to mood because some studies have already indicated an association between women and depression [22, 23]; women are also known to report psychological symptoms more frequently than men. Our findings in relation to race are in accordance with the study of Janosky et al. [24] in which whites had more depressive symptoms than non-whites. For the management of cancer-induced anxiety and depression, a psychologist needs to be present in the multidisciplinary team; also, it can be done by rational use of antidepressants and anxiolytics drugs prescribed by a clinician.

The physical effects of cancer itself are well recognised; malnourishment or cancer cachexia is caused by factors such as alteration in diet, reduced appetite, hormone-induced metabolic changes, and immune activation in cancer with cytokine release [25]. Moreover, head and neck cancer patients have nutritional deficits, dysphagia, problems in swallowing, and frequently require feeding tubes because of the anatomical location of the tumour. Our findings indicate that the presence of a feeding tube is associated with lower swallowing and chewing scores; however, this cannot be interpreted to mean that the feeding tube wors- 
ened swallowing and chewing, but instead that the tube was present because swallowing and chewing had already worsened due to cancer. Low BMI was correlated with lower scores in taste and swallowing, with a similar explanation to that of the feeding tube; both BMI and the presence of a feeding tube were consequences and not the cause of the reduced domain scores. In the study of Terrel et al. [14] the feeding tube status was found to be a very strong and significant predictor of QOL; the presence of a feeding tube was associated with statistically lower scores on QOL domains; however, this was more related to physical functioning and vitality scores (feeding tubes can cause vomiting, nausea, diarrhoea, and infections) and social functioning and emotional scores (feeding tubes can cause interference with social activities and patients may feel shameful). Our study did not observe these relationships.

Finally, the worst QOL domains were pain and anxiety. Psychological-emotional distress and its management in cancer patients were discussed previously in this manuscript. Pain is the most frequent symptom in oncology, and its incidence reaches $80 \%$ in advanced cancer patients [26]. This unacceptably high prevalence exists despite great medical, pharmacological, and technological advances that were supplemented by an increased interest in pain assessment methods [27]. Adequate pain management is essential and should take into account the physiopathology and intensity of pain. Medications selected based on the two previously mentioned items should be administered at regular intervals, and it is necessary to periodically assess the pain. Patients should be informed about the possible side effects of drugs and issues related to prejudice against opioids, to ensure adherence and success in symptom control.

It is clear that research on quality of life is becoming a vital part of medical examination, and a subjective and holistic approach must always be taken into account, such as the patient's physical and mental state [28]. Initiation of treatment may be slow; it is therefore important to identify predictors of poor physical/psychological outcomes and QOL in head and neck cancer patients prior to treatment, as well as their worst domains of QOL, so that special attention may be given to individuals with predisposing factors until treatment begins. Interventions could then be optimised based on our results for patients to achieve acceptable QOL pretreatment.

\section{Limitations}

This study is limited due to the cohort, which was relatively small, limiting the conclusions that might be drawn.

\section{Conclusions}

We demonstrated that prior to cisplatin chemotherapy and radiotherapy treatment the studied head and neck cancer patients had their optimum scores in saliva and shoulder, and that the scores for pain and anxiety were the worst. We observed that a low KPS and a large tumour extension (T4) predict the worse overall QOL; therefore, special attention should be given to these patients. Other patient-related factors did not significantly influence the overall QOL.
The authors declare no conflict of interest.

There was funding of this research by Coordination for the Improvement of Higher Level Personnel (CAPES), National Council for Scientific and Technological Development (CNPQ), and São Paulo Research Foundation (FAPESP).

The authors would like to thank all the investigators who participated in this study.

\section{References}

1. Hassan SJ, Weymuller EA. Assessment of quality of life in head and neck cancer patients. Head Neck 1993; 15: 485-96.

2. Murphy BA, Ridner S, Wells N, Dietrich M. Quality of life research in head and neck cancer: a review of the current state of the science. Crit Rev Oncol Hematol 2007; 62: 251-67.

3. Karnofsky DA, Burchenal JH. The evaluation of therapeutics in cancer. In: Macleod CM, editor. Evaluation of chemotherapeutic agents. New York, Columbia University Press 1949; 191-205.

4. de Graeff A, de Leeuw JR, Ros WJ, Hordijk GJ, Blijham GH, Winnubst JA. Pretreatment factors predicting quality of life after treatment for head and neck cancer. Head Neck 2000; 22: 398-407.

5. Ganz PA, Haskell CM, Finglin RA, La Soto N, Diau J. Estimating the quality of life in a clinical trial with metastatic lung cancer using the Karnofsky Performance Status and the Functional Living Index-Cancer. Cancer 1988; 61: 849-56.

6. Long SA, D’Antonio LL, Robinson EB, Zimmerman G, Petti G, Chonkich G. Factors related to quality of life and functional status in 50 patients with head and neck cancer. Laryngoscope 1998; 106: 1084-8.

7. Hammerlid E, Mercke C, Sullivan M, Westin T. A prospective quality of life study of patients with laryngeal carcinoma by tumor stage and different radiation schedules. Laryngoscope 1998; 108: 747-59.

8. Jindal SK, Malik SK, Dhand R, Gujral JS, Malik AK, Datta BN. Bronchogenic carcinoma in Northern India. Thorax 1982; 37: 343-7.

9. Whitcomb DC, Yadav D, Adam S, et al. Multicenter approach to recurrent acute and chronic pancreatitis in the United States: the North American Pancreatitis Study 2 (NAPS2). Pancreatology 2008; 8: 520-31.

10. Rogers SN, Lowe D, Fisher SE, Brown JS, Vaughan ED. Health-related quality of life and clinical function after primary surgery for oral cancer. Br J Oral Maxillofac Surg 2002; 40: 11-8.

11. Vartarian JG, Carvalho AL, Yueh B, Furia CL, Toyota J, McDowell JA, Weymuller EA Jr, Kowalski LP. Brazilian-Portuguese validation of the University of Washington Quality of Life Questionnaire for patients with head and neck cancer. Head Neck 2006; 28: 1115-21.

12. Alisson PJ. Alcohol consumption is associated with improved health-related quality of life in head and neck cancer patients. Oral Oncol 2002; 24: 140-7.

13. Duffy SA, Terrel JE, Valenstein M, Ronis DL, Copeland LA, Connors M. Effect of smoking, alcohol, and depression on the quality of life of head and neck cancer patients. Gen Hosp Psychiatry 2002; 24: 140-7.

14. Terrel JE, Ronis DL, Fowler KE, et al. Clinical Predictors of Quality of Life in Patients with Head and Neck Cancer. Arch Otolaryngol Head and Neck Surg 2004; 130: 401-8.

15. Psoter WJ, Aguilar ML, Levy A, Baek LS, Morse DE. A preliminary study on the relationships between global health/quality of life and specific head and neck cancer quality of life domains in Puerto Rico. J Prosthodont 2012; 21: 460-71.

16. Schag CC, Heinrich RL, Ganz PA. Karnofsky performance status revisited: reliability, validity and guidelines. J Clin Oncol 1984; 2: 187-93.

17. Schag CC, Ganz PA, Wing DS, Sim MS, Lee JJ. Quality of life in adult survivors of lung, colon and prostate cancer. Qual Life Res 1994; 3: $127-41$.

18. Hammerlid E, Taft C. Health-related quality of life in long-term head and neck cancer survivors: a comparison with general population norms. Br J Cancer 2001; 84: 149-56. 
19. Hammerlid E, Bjordal K, Ahlner-Elmqvist M, et al. A prospective study of quality of life in head and neck cancer patients. Part I: At diagnosis. Laryngoscope 2001; 111: 669-80.

20. Rapport Y, Kreitler S, Chaitchik S, Algor R, Weissler K. Psychosocial problems in head-and-neck cancer patients and their change with time since diagnosis. Ann Oncol 1993; 4: 69-73.

21. List MA, Mumby P, Haraf D, Siston A, Mick R, MacCracken E, Vokes E. Performance status and quality of life outcomes in patients completing concomitant chemo-radiotherapy protocols for head and neck cancer. Qual Life Res 1997; 6: 274-84.

22. Ross CE, Bird CE. Sex stratification and health lifestyle. J Health Soc Behav 1994; 35: 161-78.

23. Bebbington PE. Sex and depression. Psyhol Med 1998; 28: 1-8.

24. Janosky JE, South-Paul JE, Lin CJ. Pain and depression in a cohort of underserved, community-dwelling primary care patients. J Am Board Fam Med 2012; 25: 300-7.

25. Ravasco P, Monteiro-Grillo I, Vidal PM, Camilo ME. Nutritional deterioration in cancer: the role of disease and diet. Clin Oncol 2003; 15: 443-50.

26. Haugen DF, Hjermstad MJ, Hagen N, Caraceni A, Kaasa S, European Palliative Care Research Collaborative. Assessment and classification of cancer breakthrough pain: a systematic literature review. Pain 2010; 149: 476-82.

27. Hjermstad MJ, Fainsinger R, Kaasa S, European Palliative Care Research Collaborative (EPCRC). Assessment and classification of cancer pain. Curr Opin Support Palliat Care 2009; 3: 24-30.

28. Farbicka P, Nowicki A. Selected aspects of palliative care and quality of life at the terminal stage of neoplastic disease. Contemp Oncol (Pozn) 2012; 16: 506-11.

\section{Address for correspondence}

Marília Berlofa Visacri

University of Campinas

Rua Alexander Fleming, 105

13083-881 Campinas, Brazil

e-mail: mariberlofa@gmail.com

Submitted: 10.06 .2014

Accepted: 11.09 .2014 